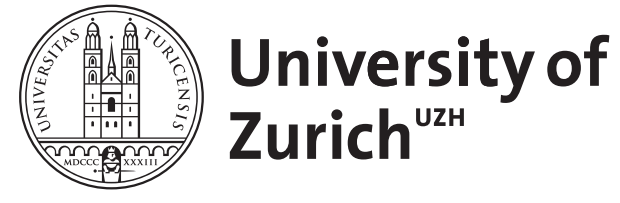

Zurich Open Repository and Archive

University of Zurich

University Library

Strickhofstrasse 39

CH-8057 Zurich

www.zora.uzh.ch

Year: 2013

Reflective intubation: a simple and effective method to improve intubation conditions by elevating the tip of the tube without additional equipment

Biro, Peter

DOI: https://doi.org/10.1093/bja/aet266

Posted at the Zurich Open Repository and Archive, University of Zurich ZORA URL: https://doi.org/10.5167/uzh-78583

Journal Article

Accepted Version

Originally published at:

Biro, Peter (2013). Reflective intubation: a simple and effective method to improve intubation conditions by elevating the tip of the tube without additional equipment. British Journal of Anaesthesia, 111(3):505506.

DOI: https://doi.org/10.1093/bja/aet266 


\title{
Reflective intubation: a simple and effective method to improve intubation conditions by elevating the tip of the tube without additional equipment
}

\section{P. Biro}

\author{
Institute of Anaesthesiology, University Hospital Zurich, Zurich, Switzerland
}

Fortunately, the majority of tracheal intubations by means of direct laryngoscopy is easy and can be successfully managed by ordinary trained anaesthesiologists without recurring to additional instruments or alternative methods. In the broad spectrum of intubation difficulties, from the very simple to the most difficult ones, there is a rather large portion of cases, where we encounter mild or moderately severe problems to secure the airway. This is typically the case in Cormack \& Lehane $2^{\circ}$ viewing conditions, ${ }^{1}$ which in the hands of less experienced personnel might become challenging to master. These moderate intubation difficulties are more frequent than the really nasty ones and usually can be overcome by rather simple means, such as altering the head position and/or neck extension, the insertion of a malleable stylet into the tracheal tube, by switching to different laryngoscope blades, or by using visually augmented equipment. ${ }^{2,3}$

A common way to cope with an unexpected moderately difficult laryngeal view (e.g. a Cormack \& Lehane $2^{\circ}$ ) is to interrupt the ongoing intubation attempt and to demand the insertion of a malleable stylet into the tracheal tube by an assisting person. ${ }^{4}$ This incident prolongs the whole intubation procedure and leaves more time for the occurrence of additional problems such as aspiration of gastric content, hypoxemia and hypercarbia. ${ }^{5}$ Repeated attempts of laryngoscopy may have undesired effects on the temporomandibular joint and dentition as well. ${ }^{6}$ Therefore it's a justifiable concern to limit the duration and number of laryngoscopies and to search for methods how to increase the success rate of the very first intubation trial. Another means to bend the tube to a more convenient shape is the subsequent insertion of a Flex-It ${ }^{T M}$ stylet (FIS, Parker Medical, Highlands Ranch, CO), which can be temporarily locked into a more pronounced curvature. ${ }^{7,8}$ If the ability to change of the tube shape is a priori intended, the choice of an Endotrol $^{\mathrm{TM}}$ tracheal tube with an inbuilt bending ability might be preferable. ${ }^{9}$ In contrast to these equipment related and to some extent costly alternatives, a purely procedural improvement of the view under ongoing laryngoscopy has been already long ago suggested, as is the case with the laryngeal lift. ${ }^{10}$ A very simple and expedient approach to manually modify the tracheal tube's shape during the ongoing laryngoscopy is described here.

The "reflective" intubation technique intends to facilitate intubation by adding a specific additional move during its performance without the necessity to interrupt laryngoscopy. It neither needs the application of a bigger force on the laryngoscope to improve the glottis view, nor the use any additional equipment. The "trick" is to gently press the tube shaft with the middle finger of the right hand on a point $2 \mathrm{~cm}$ above the dental row into its concave side in direction of the tube's convexity, while using the upper dental row (or the upper gums in edentulous patients) as a hypomochlion. (Fig. 1). This move inevitably causes a more pronounced bending of the entire tube and decreases the curve radius, which is given by its original shape. Consequently, both ends of the tube approach each other; however, the relevant benefit happens in the pharynx, where the resulting upward move of the tube tip can be translated into an approach to the glottis opening, which in turn facilitates intubation. According to direct assessment, the net effect of this maneuver is equal to an improvement of the Cormack \& Lehane view by one grade. However, this statement is based only on personal observation of the tracheal tube's physical behavior and still has to be substantiated (or rejected) by future investigations. 
This simple and unpretentious move became by time an integral part of the regular intubation technique of the author of this article, and it may have substantially contributed to his overall success rate. However, this change in the technique happened intuitively and developed in a natural way while it has never been consciously noticed when it became a standard habit. Therefore it remained unknown until colleagues who watched this approach, wondered about the nature of this specific move. This was the initial trigger to produce and publish this report. Hopefully, this herein presented simple and effective method will gain some attention and productive use. A prospective investigation to assess its influence on the outcome of tracheal intubations in patients will follow soon.

\section{References}

1 Cormack RS, Lehane J. Difficult tracheal intubation in obstetrics. Anaesthesia 1984; 39: 110511

2 Aziz M. Use of video-assisted intubation devices in the management of patients with trauma. Anesthesiology clinics 2013; 31: 157-66

3 Byhahn C, Cavus E. Airway management disasters in the ICU - lessons learned? Critical care 2012; 16: 162

$4 \quad$ Levitan RM, Pisaturo JT, Kinkle WC, Butler K, Everett WW. Stylet bend angles and tracheal tube passage using a straight-to-cuff shape. Academic emergency medicine : official journal of the Society for Academic Emergency Medicine 2006; 13: 1255-8

5 Sakles JC, Chiu S, Mosier J, Walker C, Stolz U. The importance of first pass success when performing orotracheal intubation in the emergency department. Academic emergency medicine : official journal of the Society for Academic Emergency Medicine 2013; 20: 71-8

6 Gaudio RM, Barbieri S, Feltracco P, et al. Traumatic dental injuries during anaesthesia. Part II: medico-legal evaluation and liability. Dental traumatology : official publication of International Association for Dental Traumatology 2011; 27: 40-5

7 Turkstra TP, Jones PM, Ower KM, Gros ML. The Flex-It stylet is less effective than a malleable stylet for orotracheal intubation using the GlideScope. Anesthesia and analgesia 2009; 109: $1856-9$

8 Kristensen MS. The Parker Flex-Tip tube versus a standard tube for fiberoptic orotracheal intubation: a randomized double-blind study. Anesthesiology 2003; 98: 354-8

9 Cattano D, Artime C, Maddukuri V, et al. Endotrol-tracheal tube assisted endotracheal intubation during video laryngoscopy. Internal and emergency medicine 2012; 7: 59-63

10 Krantz MA, Poulos JG, Chaouki K, Adamek P. The laryngeal lift: a method to facilitate endotracheal intubation. Journal of clinical anesthesia 1993; 5: 297-301 
Fig. 1

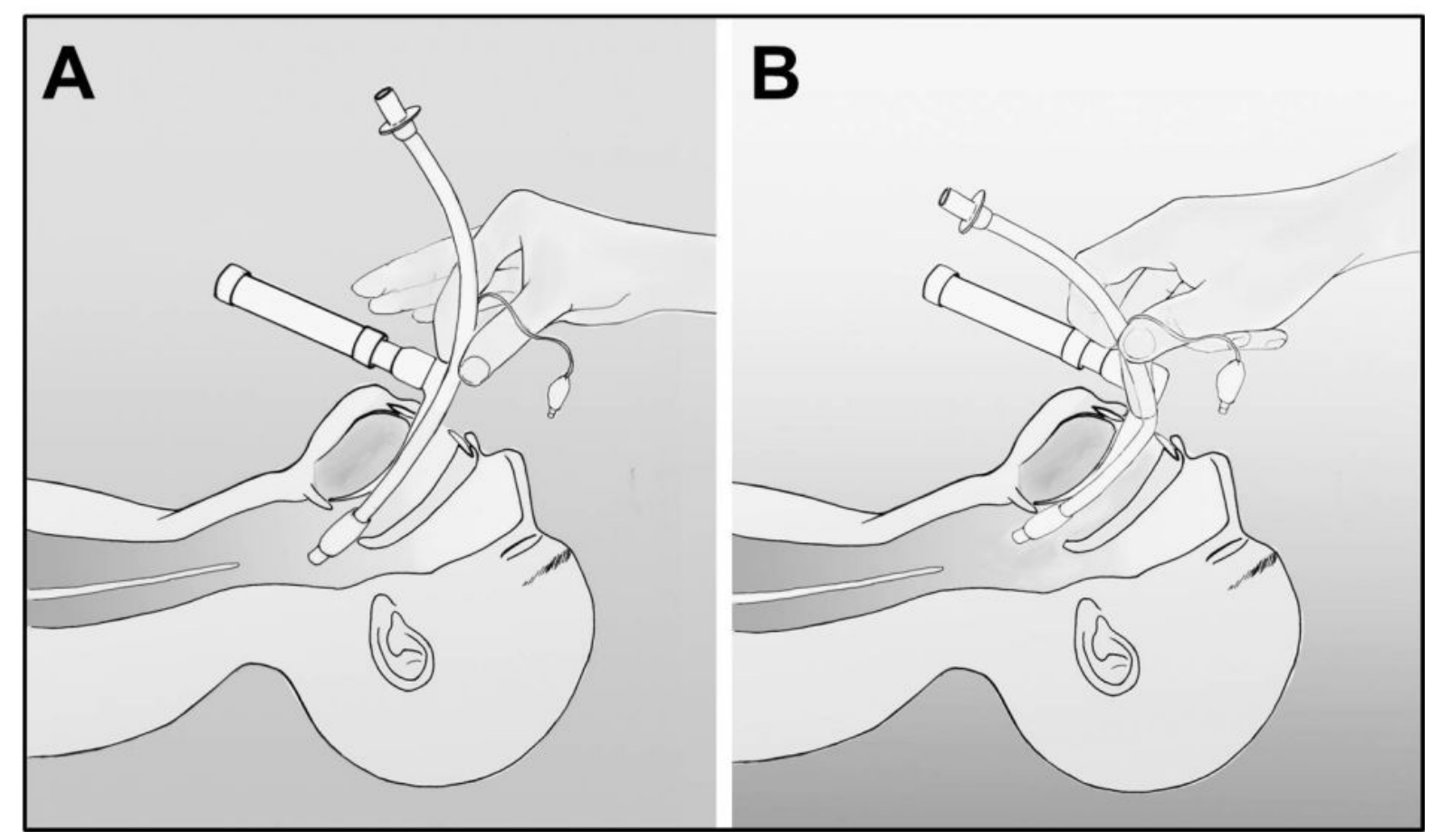

\section{Legend to the Figure}

Reflective intubation in 2 stages. A: direct laryngoscopy (left hand is not visible) and introduction of the tracheal tube into the hypopharynx. Note that the distal end of the tube points towards the oesophagus. B: by slightly upward pressing the tube shaft with the middle finger $2 \mathrm{~cm}$ above the dental ridge, an anterior bending of the tube results and the tube tip points towards the glottis. 